\title{
Study on the Administrative Divisions in China's Border Areas from the Perspective of Nation-state Building --- Changes to the Administrative Divisions in Inner Mongolia in the 20th Century
}

\author{
Sun Jing ${ }^{1}$ \\ ${ }^{1}$ School of Literature, Jinan University, Guangzhou, China \\ Correspondence: Sun Jing, No. 6 Students Dormitory, Shipai Campus, Jinan University, Tianhe District, \\ Guangzhou, China. E-mail: 568311722@qq.com
}

Received: April 1, $2018 \quad$ Accepted: April 24, $2018 \quad$ Online Published: May 28, 2018

doi:10.5539/ass.v14n6p98

URL: https://doi.org/10.5539/ass.v14n6p98

\begin{abstract}
From the end of the Yuan Dynasty to the early Qing Dynasty, when Inner Mongolia was still a special administrative region of the Qing Empire, the Mongolian nomad's territory went through numerous significant changes. Since the beginning of the $20^{\text {th }}$ century, the administrative divisions in Inner Mongolia underwent three major changes and after continuous integration they were incorporated into the administrative territory of the People's Republic of China in a manner that was compatible with the behavior of a modern nation-state. Such changes can neither be ascribed to the natural process of national development and it's accompanying fissions nor to the sinocization of Inner Mongolian initiated by Han migrants. Instead, it is derived from the game of power played in the region by various forces, from the Manchu and Han peoples, to the Mongolians, Russians and Japanese, and the Kuomintang and the Chinese Communist Party in the period of surging modern nationalism. This is evidenced by the changes of division in Hulunbuir in particular. This case is enough to demonstrate that the issues of China's border and nations are not simply equivalent to the binary opposition between Central Plains and border areas, between Han and ethnic minorities, but a process teeming with complex and diverse points of contention, political wrestling matches and other interactions.
\end{abstract}

Keywords: territory of Mongolian nomads in Qing Dynasty, changes of administrative division in Inner Mongolia, Chinese nationalist movement, national identity

\section{Introduction}

As China continues to experience social transformation, ethnic issues have emerged, prompting discussions in mainland Chinese academia on issues related to the "depoliticization of ethnic issues" and "second generation of national policy." Some argue that the system of regional ethnic autonomy and preferential policies for minorities, borrowed rigidly from the Soviet Union, has led to the solidification of ethnic identity and a weakening of national identity. Therefore, the government should "depoliticize" ethnic issues and adjust preferential policies for minorities so as to strengthen the identity of the Chinese nation. Some, however, think otherwise. They maintain that the system of regional ethnic autonomy should be advanced without any irresolution for it is in keeping with China's national conditions. Despite their divided opinions, their viewpoints and ways of thinking are all colored by theories concerning western nationalism and compare the situation to relevant cases in the US and the like. Meanwhile, few have investigated the history of China's ethnic policies, systems of regional ethnic autonomy, or other related ethnic issues.

In addition, views like the "New Qing History" passed to us from the western world have sought to reinterpret and rewrite Chinese history by placing "frontier" and "ethnic minorities" as the mainstay. In this way, the role ethnic minorities in the Qing Dynasty played in the building of the modern Chinese nation-state is elevated to crucial importance (Yao, 2014; Mao, 2016), and the traditional Central-plains-centered Chinese history (or history of the Chinese empire) is replaced by a "history of an empire built by frontier nomads." Notwithstanding the changing protagonists of history, the binary opposition between the Central Plains and border areas, between the Han and the ethnic minorities does not change in essence. In fact, this binary understanding of the relationship is far from explanatory, and in "the story of China," the establishment of the system of regional ethnic autonomy as a product of the influence of the Soviet Union still needs to be understood. The cases 
discussed in this paper will elaborate on this point.

This paper focuses on the changes in the administrative divisions in Inner Mongolia in the 20th century, a period crucial to the birth and development of the Chinese nationalist movement and China's Transformation toward Modern Society. As an area which shares borders with Russia, Mongolia and eight provinces in mainland China, Inner Mongolia boasts a vast wealth of land and resources as well as a population with a complex demographic. Consequently, changes of the administrative divisions in Inner Mongolia are of great importance to China's military strategy, ethnic relations, frontier development, etc.

The existing research into the administrative divisions of Inner Mongolia concentrate on the process and successful practices of the merge of Inner Mongolia and Suiyuan, Suiyuan peaceful liberation, regional national autonomy under the leadership of the Chinese Communist Party and so on (For example: Tang, 2014; Li, 2008; Qinggeletu, 2003; Xu, 2013). Study on the Changes of Administrative System in Modern Inner Mongolia (Menghebaoyin, 2012) written by Meng Hebaoyin epitomizes this level of research. This book, using historical and sociological research methods, reviewed the vicissitudes of the administrative system in Inner Mongolia from the Qing Dynasty entered into Shan Haiguan to the found of the People's Republic of China, and is based on rich historical materials, it displays the evolution and interaction of the Mongolian Banner administrative system and province-county administrative system in modern Inner Mongolia. It, however, fails to unchain the narrative from the perspective of Mongolian-Han duality and limits its research focus to Inner Mongolia. In fact, the changes of administrative divisions in Inner Mongolia are correlated with those in Outer Mongolia, Heilongjiang, Xinjiang, Qinghai, and even Buryatia in eastern Russia, and with the broader historical processes that countries like China, Mongolia, Russia, and Japan underwent in the 20th century. However, this kind of content is left out of this book.

This paper will simply review the changes of the administrative divisions in Inner Mongolia which have occurred since the 20th century, and then grant comprehensive consideration to the more intricate aspects of the subject. The historical picture it represents will go well beyond the binary structure of past research into this area, which often contrast the Central Plains and frontier areas, Han and non-Han Chinese. Instead this paper seeks to unfold the complex relationships that cover the gradual involvement of forces including the forces of Manchu, Han, Mongolia, Russia, Japan, KMT and the CPC, and the power-games and connections in various sectors among them.

\section{Chapter 1}

In the Qing Dynasty (Note 1), Mongolia was vast in its nomadic territory, of which Inner Mongolia was only a small part. Since 1912, the region has undergone three major changes in its administrative divisions.

The first change occurred in 1912, as the old era was replaced by a new one at the end of the Qing Dynasty and the foundation of the Republic of China. At that time, Outer Mongolia and Hulunbuir announced their "independence/autonomy" successively. Meanwhile, the government of the Republic of China accordingly adjusted the administrative division, reorganizing the region into three Special Areas-Jehol, Chahar and Suiyuan. Jehol included the Josutu and Juuuda Leagues (a prefecture-level division), plus the Chengde area (now in northern Hebei). Chahar comprised of Xilingol League and Xing'he region as well as much of the former territory of the Eight Banners (a county-level division) of Chahar. Suiyuan consisted of Ulanqab League, Ih-Ju League, the Guihua Tumed Banner and the Suiyuan region. In 1928, the government turned the Special Areas into provinces, along with two newly founded provinces: Qinghai and Ningxia. As a result, the Khoshut tribe was administered by Qinghai Province, and Ejin Banner plus Alxa Banner by Ningxia Province. So far, the leagues and banners of Inner Mongolia had been converted into provincial or county-level administrative regions.

The second administrative change took place in 1932 when the Japanese invaders established a puppet state of Manchukuo. At that time, Japan had been wrestling with Russia for an extended period, and the Japanese were thus paying great attention to Mongolian issues. To colonize the country in general by availing the power of the Mongolians and the Manchu people, Japan sponsored the foundation of two puppet states of Manchukuo with Puyi as the nominal regent and emperor and of Mongol United Autonomous Government with Mongolian prince Demchugdongrub (also known as Prince De) as the chairman. Besides, Hsingan Province was created as a special administrative sub-division under the control of "Manchukuo". Later, the province was divided into four parts-Hsingan North (former Hulunbuir region), Hsingan South (former Seven Banners of Jirem League), Hsingan East (formerly within the jurisdiction of Buteha General Yamen) and Hsingan West (terriroty of Juuuda league to the North of Xar Moron River in the past).

Japan did not separate this area according to geometric lines of latitude and longitude as if it was a no-man's land. 
Instead, the four sub-provinces were demarcated in consideration of past divisions created around military areas which were formed during the Qing Dynasty and the early years of the Republic of China and different agricultural and pastoral areas which had formed long ago. The Japanese also sought to create a balance between the size of the four sub-divisions and between the powers wielded by the various Mongolian banners and counties (Note 2). The Japanese colonizers adopted a different approach from their European counterparts. According to Benedict Anderson, when European colonizers were mapping the world, "the entire planet's curved surface had been subjected to a geometrical grid which squared off empty seas and unexplored regions in measured boxes" (Benedict Anderson, 2011). They turned the planet into a picture marked with longitudes and latitudes, casting aside factors like traditional customs and practices, ethnicity or other unique features, or the history and status quo of the colonized region. Japanese colonizers in Inner Mongolia, on the other hand, considered more or less the unique traits of Mongolian ethnicity. The most typical example is that they renamed “Guisui” Hohhot ( “厚和豪特”). The town emerging in the Ming Dynasty was called Kokegota (“库库和屯” ) in Mongolian, referring to a green city. During the Ming and Qing Dynasties the town was twice renovated and given names of "Guihua" and "Suiyuan" (the two names were mixed into "Guisui" later), meaning to gain far-reaching control of the country. The town's name exudes the sense of subjugation by another nation. During Japanese colonization, the town was renamed Hohhot, of the same sound with Kokegota, and retaining its original meaning. At the same time, Hohhot was upgraded to a Special Administrative City. With this, the city established its political status in western Inner Mongolia. Japan and European countries were poles apart in their colonial polices. This may have something to do with the psychology of Japan as a new colonial empire and the highly complicated situation in the colonized region where various parties were in play.

The creation of Hsingan Province integrated the inhabited areas of eastern Mongolia which had been split since the Republic of China. In addition, Mongolians in Hulunbuir and Inner jasagh Mongolia in the Qing Dynasty were under the same jurisdiction and management style for the first time ever. Meanwhile, the foundation of the Province divided the land of the leagues of Jirem, Juuuda and Josutu into different provinces. Since then, the Josutu League has been geographically separated (Note 3). Besides, the merger of Hsingan Province and the Mengjiang (also known as Mongol Border Land) led to the secession of Eastern Mongolia and Western Mongolia.

The third administrative change occurred between 1947 and 1954. With the surrender of Japan, Hsingan Province and the Mengjiang United Autonomous Government collapsed. Inner Mongolia was stuck in a power vacuum for a while, and the Mongolian nationalists began to establish authorities for self-government one after another. There are three examples of these authorities. The first authority was the People's Autonomous Government of East Mongolia, covering the autonomous regions of Jirem League, Juuuda League, Josutu League and Hulunbuir, the second Buteha tribe, the E Ke Ming An, Qiqihar, and the banner of Soulouque. The second one was the Interim government of the People's Republic of Inner Mongolia, which was reorganized into The Federation of the Inner Mongolian Autonomy Movement after the inter-coordination of the CPC and Ulanhu. The third one is The Autonomous Government of Hulunbuir, with Eerqinbatu, the former governor of North Hsingan Province, as the chairman. Such a political situation would definitely raise the attention and rivalry of many forces. With their sincerity and wisdom, the $\mathrm{CPC}$ won the recognition of the Mongolian nationalists. After several negotiations, on May 1, 1947, the Inner Mongolian Autonomous Government was set up, having jurisdiction over Hsingan League, Nunmoron League, Xilingol League, and Chahar League, and it was located at Wangyemiao (Ulanhot). On January 1, 1948, the local autonomous government of Hulunbuir was revoked and reorganized into the Hulunbuir League, within the jurisdiction of the Inner Mongolian Autonomous Government. After the liberation of the whole of Northeast China, both the Jirem League, formerly in the jurisdiction of Liaobei Province, and the Juuuda League, formerly in the jurisdiction of Rehe Province, officially became part of the Inner Mongolian Autonomous Government in May, 1949. With the successive liberation of Suiyuan, Alxa, and Egin, the whole Mongolian area was liberated. After the completion of the regional merging of Inner Mongolia and Suiyuan in June, 1954, the center of the Inner Mongolian Autonomous Government was moved from Zhangjiakou to Hohhot (It was renamed as “呼和浩特”), thus forming the contemporary appearance of the Inner Mongolian autonomous region. By that time, the territory of the Mongols in the Qing Dynasty had been partially recovered, and Inner Mongolia, which had been broken up several times since 1912, was eventually reintegrated in a new way.

\section{Chapter 2}

The transitions that the Inner Mongolian administrative division underwent in the $20^{\text {th }}$ century were not only due to the natural fissions of their multi-ethnic society. It took shape within the context of conflicts shaped by many forces such as the Manchu, Han, Mongols, Russians, Japanese, KMT and CPC, as imperial colonialism and 
nationalist movements prevailed. The most typical example of this transition occurred in the region of Hulunbuir.

Hulunbuir, where the Ewenki, Oroqen, Daur peoples and the Mongols lived together, was divided into the eight banners of Buteha, Solon and Barga by the Qing Authority. It was regarded as a part of Inner Mongolia and governed by Heilongjiang General at that time. Since the establishment of Heilongjiang Province, Hulunbuir has officially belonged to Heilongjiang Province.

Administrative reform for Mongolia and the permission to cultivate virgin land in the late Qing Dynasty damaged the rights of Hulunbuir, thus accelerating the disloyalty of Mongols in this region. However, Russia's control and impact over it had been increasingly intensified by the establishment of the Chinese Eastern Railway. After Outer Mongolia's declaration of "independence", the feudal upper class led by Oriat Director Sheng Fu and New Barga Director Che Hezha immediately deployed forces armed with guns supplied by Russia. They attacked and occupied Hailar City, declared independence and sent documents of allegiance to Outer Mongolia. Therefore, this issue has always been regarded by researchers as a concrete example of an action taken by the emergent Mongolian nationalist movements at that time. However, the situation was relatively complex, considering the leaders and the flags they fought under in this revolt. The force led by Sheng Fu raised the flag of the "Great Qing Dynasty Volunteer Army" instead of the Mongolian National flag, as they considered Hulunbuir Mongols to be a part of the Qing Dynasty who refused to proclaim their allegiance to The Republic of China. They acknowledged that the Hulunbuir banner-men as a small part of the Qing dynasty who never fully merged with the republic. This is remarkable considering that the Hulunbuir flags were those of Inner Mongolia and Sheng Fu himself, the Oriat Director, was directly assigned to his position by the Qing Government, although the nature of his position and his range of power was quite different from that of the Jasaqs of Jasaq, Inner Mongolia. Sheng Fu was a remaining official of the Qing Dynasty, rather than a Mongolian nobleman, thus he held the view that he should fulfill his responsibility to the Qing Government on account of the grace they had shown him over the generations. (Buladuqige, Jin, \& Sai, 2002)

After the Hulunbuir event, the new Governor of the Northeastern Qing Government, Zhao Erxun, immediately appointed the grand coordinator of Heilongjiang Province to tackle the rebels. At the same time, he delegated Du Mengtian and Yu Jiaming to propitiate with Sheng Fu. Sheng Fu felt regret for the first time and canceled his drive for independence. At that point, in order to facilitate the independence of Hulunbuir, on the one hand, Russia obstructed the suppression of Heilongiiang authority with the excuse of taking the rights of the Chinese to use the Eastern Railway away. At the same time, Russia threatened Sheng Fu that defying China's provocation wouldn't help him and the charge for the borrowed guns - a huge amount of money - needed be paid. As a result, Sheng $\mathrm{Fu}$ compromised and overturned his previous resolutions at once. Heilongjiang authority then sent Qing Shan, governor assistant of the eight banners, and Jiao Jingming, valiant general, to Hulunbuir to propitiate Sheng $\mathrm{Fu}$, but Sheng Fu recalled his decision again. All of this resulted in a fierce brawl between Hulunbuir's Mongolian forces and the Chinese army in Lu Bin Prefecture (now called Manchuria). Russian soldiers disguised themselves as Mongols to join the battle, shocking the Chinese government. Then Sheng Fu's group seized Lu Bin Prefecture, Jilalin and other places rapidly, and took control of the whole Hulunbuir. In May, 1912, Jebtsundamba conferred Sheng Fu as "beizi" (Note 4) and Hulunbuir Minister and awarded him with the silver seal. At this point, Hulunbuir was part of Yeke Mongghol Ulus, and paid taxes to the Cullen Government. Heilongjiang authority strongly condemned Russia's deceit in that they pretended to be neutral but were in fact supporting the independence of Hulunbuir. The government planned to dispatch troops to recapture Hulunbuir, but under the threat of Russia, no achievement was made. At the same time, Russia had gained huge benefits in Hulunbuir. Considering the vested interests and the international situation, in November, 1915, Russia signed the Sino - Russian Treaty of Hulunbier directly with the Chinese authority without Sheng Fu's awareness. In the treaty, Russia recognized "Hulunbuir as a special area under the direct control of the Central Government of the Republic of China" and required the Chinese government to accept all kinds of contracts it had signed with the Sheng Fu authority. Since then, the Hulunbuir region became a "special area" that was namely "self-governed" by Sheng $\mathrm{Fu}$ and other members of the Mongolian upper class and was actually controlled by Russia. (Note 5)

Outer Mongolia didn't fully grasp its own economic lifelines after it gained "independence." Moreover, due to the enormous amounts it had spent on its military during the war years, its economy was hit by severe crisis. Furthermore, all of the expenditure and the daily spending of the Mongolian feudal nobility was collected from the lower populace of Ejin Horo Banner, leaving people with no way to make a living. In addition, the strife between monks and lay people from the upper political ranks put Outer Mongolia into further political and economic crisis. However, after the October Revolution in 1917, the Republic of China gained more influence amid the weakening of the Russian Empire's power. Then, the Jebtsundamba regime (Outer Mongolia) turned to China for "protection". On November 17, 1919, the Outer Mongolian Prime Minister and Interior Minister 
Gonchigjalzangiin Badamdorj, and Foreign Minister Balingiin Tserendorj signed a document that contained a plea to abdicate Outer Mongolia's autonomy to Chinese rule and a claim to make all treaties previously signed with Russia invalid, stamped it with the seal of Jebtsundamba and sent it to Beijing. On November 22, the same year, Xu Shichang, the then President of the Republic of China, officially issued an order to approve the removal of Outer Mongolia's autonomy and claimed that the feudal nobility of Outer Mongolia such as Jebtsundamba Khutuktu would still enjoy the same reverence and mileage (Note 6). The falling of the Russian Empire and the removal of Outer Mongolia's autonomy took away all support for the Sheng Fu regime, while the White Army of Russia and the Japanese army escalated their provocation and ravage in Hulunbuir region, causing uncertainty to the Sheng Fu regime's independence. And in 1918, the garrison commander of the Chinese Eastern Railway in Heilongjiang Province sent troops to Hulunbuir, further increasing the Chinese government's influence in the region. On December 21, 1919, Hulunbuir's new Vice Governor Guifu thereupon, called upon Beijing to cancel Hulunbuir's autonomy. On January 28, 1920, after negotiations, the then President of the Republic of China Xu Shichang announced the withdrawal of Hulunbuir's "special region" status and let Heilongjiang Province have jurisdiction over it.

When Mongol banners were first set up in Hulunbuir during the Qing Dynasty, Hulunbuir's governance differed from that of the Inner Jasaq Mongolia.As for its affiliation, Hulunbuir has always been under Heilongjiang's jurisdiction except for the period of short-term autonomy from 1912 to 1920 . The establishment and elimination of its autonomy were not so much a natural result of the development of the Mongolian nationalist movement as it was the outcome of conflicts between China, Mongolia, Russia, and Japan. From the historical, geographical and folkloric perspective, Hulunbuir and Heilongjiang were more closely related. But, why did the central government assimilate it into the Inner Mongolian Autonomous Region after its establishment in 1947? This was related to Japan's colonization of East Mongolia and the way in which the 1945 national autonomous movement unfolded in the eastern part of Inner Mongolia.

During the "Manchukuo" period, Hulunbuir was fused into the territory of Hsingan North and was first united with the other leagues of Inner Jasaq Mongolia. In August 1945, in the hope of help from the Soviet Union in the fight against Japan in the Northeast China, the Nationalist Government of the Republic of China signed The Treaty of Friendship and Alliance with the Soviet Union. According to the treaty, the independence of Mongolia would be decided through a referendum and the National Government would have to accept the result. The treaty also stipulated that, the Soviet Union should send troops to Northeast China, never interfere with the Chinese government's sovereignty and territorial integrity in the region and withdraw within three months after Japan's surrender. At that time, Outer Mongolia was the Mongolian People's Republic as a result of their declaration of independence in 1924, and the Mongolian nationalist movement was not yet quelled. After Japan's surrender, the eastern region of Inner Mongolia including the Hulunbuir fell into a state of uncertainty about its national future. Some people suggested hopes for uniting Inner Mongolia with Outer Mongolia, which were countered with rejection from Outer Mongolia because of the Yalta agreement and indifference from America because of it's relationship with the two political super powers, China and the Soviet Union. With the support of the Soviet Union and Outer Mongolia, Buyanmandu and Ha Feng'a formed the East Mongolian People's Autonomous Government, and established Nunmoron province which was made up of the Arun Banner, Morin Dawa Banner and the Buteha Banner (present name's Evenk) on the west side of the Hulunbuir mountain. Furthermore, dozens of Mongol and Daur political figures including Erkimbatu formed the Hulunbuir Autonomous Government. These two political forces sent representatives to negotiate with both the Kuomintang and the Communist Party about their proposals for autonomy. They were stringently rejected by the Kuomintang yet gained the support of the Chinese Communist Party. In March 1946, the Northeast Administrative Committee approved that the Hulunbuir area would maintain its status quo. After the withdrawal of the Soviet army, the local Hulunbuir Mongolian armed forces and the Northeast Democratic Army jointly repelled the "Guang Fu" Army of the Kuomintang and a group of bandits.

In the meantime, Ulanhu led the autonomous movement of Inner Mongolia and conducted rounds of talks with the East Mongolian People's Autonomous Government. Both sides approved of The Federation of the Inner Mongolian Autonomous Movement acting as the united leading bodies of the Inner Mongolian autonomous movement. On May 1, 1947, the Inner Mongolian Autonomous Region, the first ethnic autonomous region in China, was established and the government was set up in Wangyemiao (Ulanhot). Ulanhu was elected as the chairman and Ha Feng'a was elected as the vice chairman of the government.In early November, The Autonomous Government delegates including Erchinbaku, Konkuoerjabu, Dugaerjabu and Khata arrived at Ulanhot at the invitation of the Autonomous Government of Inner Mongolia. Both sides held a talk on issues regarding the unity of Mongolia. After negotiations, they agreed to establish Hulunbueir, which then had its 
jurisdiction over areas including Hailar city, Manzhouli City, Jalainur District, Jalainur District, Yakeshi City, New Barag left Banner, New Barag Right Banner, Ergun Banner, Old Barag Banner and Sauron Banner. On January 1, 1948, Hulunbeier was established following the dissolution of the Autonomous Government of Inner Mongolia.

From then on, Hulunbuir was officially included in the domain of the Inner Mongolia Autonomous region. It can be said that the dissolution of the local autonomous forces in eastern Mongolia and the peaceful handover of the Hulunbuir regime represents a major step in the modern Mongolian national liberation movement. Hulunbuir actively collaborated with the Inner Mongolian autonomous government led by the Chinese communists in the modern Mongolian autonomous, national liberation movement. Therefore, it was enshrined as a revolutionary place of the inner Mongolian liberation movement in modern times, as such, no one could obliterate it from the historical and geographical map of Inner Mongolia, and it has consequently carried much more spiritual significance than it does administrative importance.

\section{Conclusion}

Inner Mongolia, starting as a special administrative area of the Qing dynasty, after years of continuous integration was finally incorporated into the administrative territory of the People's Republic of China in a way that suits a modern nation-state. The Hulunbuir region has always been a multi-ethnic community wherein different forces are pitted against each other. The fact that it emerged as a part of Inner Mongolia after previously being considered a corner of Heilongiiang is the direct result of the historical revolutions of the Chinese nation, Japan's colonial policies towards Manchuria and Mongolia, Outer Mongolia's nationalist movement, and the interests of The Soviet Union and the US. It is not these complicated internal and international relations that have shaped the game of power and politics in the region. Outer Mongolia's independence movement and the independence movement in Inner Mongolia provoked by Demchugdongrub, more known as Prince De, also played a significant role in the complicated situation in Inner Mongolia as it was swayed by various entangled forces. To various degrees, the Manchu, the Han, the Mongolians, Russians, Japanese, Kuomintang and the Communist party all played a part in the long-term game of related forces that led to the formation of today's Inner Mongolian autonomous region.

In the time between the late Yuan Dynasty and the Qing Dynasty, although the Mongolian nomadic territory had broadly defined borders, its boundaries continued to change, to the point where it became difficult to mark out a certain tribe as belonging to a certain country. As the Qing Dynasty and Russian Empire sought to expand their territories and to bolster their clout in the region, The Mongolian tribes who occupied areas close to the borders entered a period wherein they were subjugated and integrated into different countries.For the Mongolians, this period was highly divisive. For example, the Buryatia Mongolians of eastern Siberia, originally part of North Mongolia, traditionally fall under the auspices of Mongolia Khalkha. During the reign of Kangxi (1661-1722) Tüshiyetu Khan Aimag, a faction of the Mongolian Khalkha, submitted to the Qing Dynasty after their defeat to Galan. At this time, the Buryatia Mongolians also lost their asylum and were subject to Russian invasions. After the signing of the Treaty of Nerchinsk, the Buryatia area was completely integrated into the Russian territory. These Mongolian tribes were incorporated into different countries amid the delimitation and contention of the great powers. Meanwhile, the Mongolians never ceased to resist. In the 20th century, the Pan-Mongolian independence movement involving Outer Mongolia, Inner Mongolia, the Buryats, Xinjiang and Qinghai also indicated an outburst of rebellious consciousness among the Mongolians. Although the great discrepancies and variations among the Pan-Mongolian factions meant that it has proven impossible to achieve success in this way, it was a common aspiration for the Mongolians of all tribes to keep their own land for their herds and to assert their own interests. For the Chinese ruler of the 20th century, to recognize and respect their aspiration constituted the prerequisite for the effective integration of Mongolia.

The present administrative area of Inner Mongolia is the outcome of gradual division and the reintegration of the Mongolian nomadic territory in the Qing Dynasty. This division and reintegration was accompanied by the collapse of the regional relationship of the traditional China, and by the birth and evolution of various nationalist movements in China which is Not only the mainland but also the frontier. In the final analysis, China's Transformation toward Modern Society and the changes of the administrative area of Inner Mongolia reflect the imperialist invasion and partition of the country, and further illustrate how the modern Chinese nation-state came into being, giving witness to the fruit of the Mongolian nationalist movement. The establishment of the Inner Mongolian Autonomous Region and the settlement of issues concerning Mongolian identity set a successful example for the peaceful settlement of Xinjiang, Tibet. It not only accelerated the establishment of the new China, but also greatly reduced the possibility of infighting among the fellow compatriots there which might otherwise have occurred. Therefore, although China's current model of Regional Autonomy for Ethnic 
Minorities borrowed some aspects from the experience of the Soviet Union, it was also the historical result of the development of modern China. Furthermore, the region has the novel inheritance of the legacy of the tug-of-war between various different forces that was passed down to the Chinese Communist Party, which constituted the best option at the time given the historical context. Looking at the situation, we can't afford to negate or distort history because of existing problems, nor can we label the frontier and ethnic issues as resting on the infiltration and even assimilation of the Han culture. Furthermore, the historical complexity outlined in this essay and the entanglement of various forces and interests are far beyond the binary differences of central plains versus the frontier territories, Han versus non-Han or the dual system of central and local. All these factors must be taken into serious consideration when we think and speak about China today.

\section{References}

Anderson, B. (1936/2015). Imagined Communities: Reflections on the Origin and Spread of Nationalism (Wu Rui Ren, Trans.). Shanghai, SH:Shanghai Century Publishing House.

Buladuqige, Jin, H., \& Sai, H. (2002). General History of Mongolian Nationality (Vol. 5, Part 2). Hohhot, Hohhot: Inner Mongolia University Press.

Li, Y. W. (2008, January). The Decision and Implementation of Unified Administrative Division in Inner Mongolia during the Initial Period of New China. China's Borderland History and Geography Science. 18(1), 59-69.

Mao, S. (2016, October). From the division of nations to territory division --- Comments on Frontier China: the History of National Relations since the 21st Century by Liu Xiaoyuan. Twenty-First Century, (157), 131-141.

Menghebaoyin. (2012). Research on the Changes of Administrative System in Modern Inner Mongolia. Shenyang, SY: LiaoNing Ethnic Publishing House.

Qinggeletu. (2003, April 1). The Progressively Realization of Unified National Regional Autonomy in Inner Mongolia. Journal of Inner Mongolia University (Humanities and Social Sciences). (2), 77-82.

Tang, M. (2014). The Ethnic Factor of Administrative Division Transformation since Qing Dynasty (Master's thesis) Shandong University, Jinan, China.

Xu, K. (2013). An Initial Exploration of the Model of Suiyuan Province from the Perspective of Nation-State Integration (Master's thesis). Minzu University of China, Beijing, China.

Yao, X. Y. (2014, February). "Introspection Boom" about the Ethnic Issues in Mainland China. Twenty-First Century, (141), 31-44.

\section{Notes}

Note 1. The nomadic territory of Mongols in Qing dynasty included three major parts: 1. Six leagues made up by 49 banners in Inner Jasaq Mongolia (now called Inner Mongolia); 2. Outer Jasaq Mongolia that includes today's Outer Mongolia, the Heshuo Special Department of Qinghai, the Dzungar Department of Northern Xinjiang, the Ejin Torgout Banner and Alaxa Erut Banner of the Inner Mongolia Autonomous Region; 3. Inner Mogolia, such as the Chahar Department, the Guihua Tümed Department, the Buteha Banner and Barga Banner.

Note 2. For example, the territory of Hsingan North approximately corresponds to that of Hulunbuir in Qing dynasty. Gorlos Front Banner, Gorlos Back Banner, Dorbod Banner and E Ke Ming An Banner were not incorporated in to Hsingan province due to an agricultural belt formed between them and other Mongol banners. Menghebaoyin. (2012). Research on the Changes of Administrative System in Modern Inner Mongolia. Shenyang, SY: LiaoNing ethnic publishing house, pp. 134-153.

Note 3. The Josutu League consisted of three Kharachin Banners (Left, Middle, Right), two Tümed Banners (Left, Right), Tanggot Khalkha Banner and Shireet Khuree Banner. Through official territory adjustments, Tanggot Khalkha Banner, Shireet Khuree Banner and Kharachin Left Banner were absorbed into Hure Banner which was returned to Hsingan's jurisdiction. Chaoyang County (eliminated later) and a part of former Tümed Right Banner were emerged into a new Tümed Right Banner. Parts of former Tümed Right and Left Banner were incorporated into Tümed Middle Banner which was, along with the left part of the former Tümed Left Banner, incorporated into Jinzhou Province. The three Kharachin Banners (Left, Middle, Right) were merged into Rehe Province (Menghebaoyin, 2012, p. 138).

Note 4. Beizi: A title that shows status. 
Note 5. Historical reference for the independence movement of Hulunbuir (Buladuqige, Jin, \& Sai, 2002 , p. 216).

Note 6. The cancellation of this self-government didn't last for a long time. From the end of 1920 to the beginning of 1921, a group of Outer Mongolian nobles colluded with Mongolians who purported to be Buryats and stirred up the Pan-Mongolian Independence movement. Rngem, a henchmen of Semenoff, besieged Kulun, now known as Ulaanbaatar, and captured Jebtsundamba. In February 1921, Outer Mongolia was declared "independent" again (Buladuqige, Jin, \& Sai, 2002, p. 298).

\section{Copyrights}

Copyright for this article is retained by the author(s), with first publication rights granted to the journal.

This is an open-access article distributed under the terms and conditions of the Creative Commons Attribution license (http://creativecommons.org/licenses/by/4.0/). 